\section{Commentary: Robotic totally endoscopic coronary artery bypass: State of an art}

\author{
Saqib H. Qureshi, MBBS, MD, FRCS(CTh), and \\ Marc Ruel, MD, MPH
}

Totally endoscopic coronary artery bypass (TECAB) with robotic assistance can be performed for single left internal thoracic artery-left anterior descending or multivessel grafting, either on the beating or arrested heart, with or without recourse to a small anterolateral thoracotomy. Conventionally, handsewn coronary anastomoses are undertaken via a small left thoracotomy; however, a complete port-based approach can also be used to perform the anastomoses by using endoscopic tools such as nickel-titanium suture clips (U-CLIP; Medtronic Inc, Minneapolis, Minn) or even automated anastomotic devices such as the nowdefunct C-Port Flex (Cardica, Redwood City, Calif). TE$\mathrm{CAB}$ can achieve standalone revascularization or be part of hybrid coronary revascularization, where grafting of the anterior (left anterior descending artery) with or without lateral (circumflex artery) surfaces of the heart is combined with percutaneous coronary intervention to the remaining target vessels.

In this edition of JTCVS Techniques, Dr Balkhy, a leading robotic cardiac surgeon, shares his thoughts on TECAB and his advocacy for the adoption and development of this modality. ${ }^{2}$ In more than 900 cases, Dr Balkhy has widened the scope of the TECAB approach by incorporating even some high-risk patients.

From the Division of Cardiac Surgery, University of Ottawa Heart Institute, Ottawa, Ontario, Canada.

Disclosures: Dr Ruel reported Principial Investigator, Minimally Invasive versus STernotomy (MIST) trial and MICS CABG Proctor (both with support from Medtronic, Inc). Dr Qureshi reported no conflicts of interest.

The Journal policy requires editors and reviewers to disclose conflicts of interest and to decline handling or reviewing manuscripts for which they may have a conflict of interest. The editors and reviewers of this article have no conflicts of interest.

Received for publication April 23, 2021; revisions received April 23, 2021; accepted for publication April 28, 2021; available ahead of print May 4, 2021.

Address for reprints: Marc Ruel, MD, MPH, University of Ottawa Heart Institute, 40 Ruskin St, Ottawa, Ontario K1Y 4W7, Canada (E-mail: mruel@ ottawaheart.ca). JTCVS Techniques 2021;10:158-9

2666-2507

Copyright (C 2021 The Author(s). Published by Elsevier Inc. on behalf of The American Association for Thoracic Surgery. This is an open access article under the CC BY-NC-ND license (http://creativecommons.org/licenses/by-nc-nd/4.0/).

https://doi.org/10.1016/j.xjtc.2021.04.031

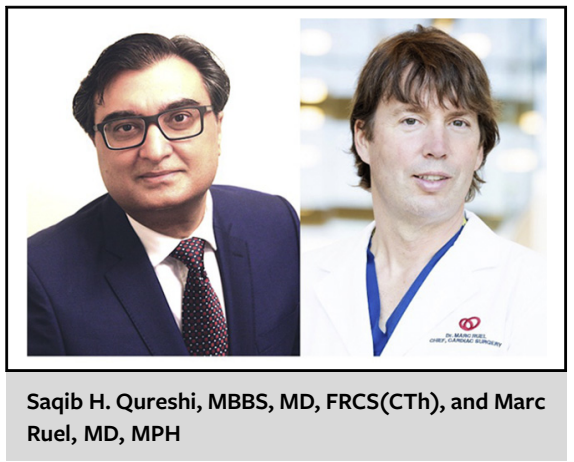

CENTRAL MESSAGE

TECAB is a demanding endeavor and requires the utmost skilled teamwork, dedication, and leadership. Involved teams should carefully appraise each step toward approaching this expertise.

The biggest advantage of a robotic approach to coronary artery bypass grafting (CABG), even if restricted to conduits takedown, is indeed the availability to harvest bilateral internal thoracic arteries while avoiding sternotomy and aortic manipulations, which may improve the functional recovery of the patient. ${ }^{3,4}$ However, there remain concerns regarding a greater incidence of transfusions, rare but eventful conversions to sternotomy or thoracotomy, early graft failure and reinterventions, ${ }^{5,6}$ a similar rate of mortality, stroke, atrial fibrillation, and renal failure compared with conventional $\mathrm{CABG} .{ }^{3}$ Costs are also high, with an initial investment exceeding several millions US dollars and additional operational costs between $\$ 100,000$ and $\$ 150,000$ per annum.

One can only share Dr Balkhy's enthusiasm and admire his expert view of the TECAB approach. However, we must also remember that TECAB has not been deemed superior to other minimally invasive approaches such as minimally invasive coronary surgery (MICS) $\mathrm{CABG}^{7,8}$ both in terms of financial implications as well as patient outcomes. As an alternative, conventional MICS CABG allows for revascularization of the entire myocardium, affords the use of bilateral internal thoracic artery or multiple arterial grafts (by way of the radial artery), is associated with very low mortality, ${ }^{7}$ and obviates the huge financial implications of TECAB.

To achieve best results with TECAB, one needs significant team commitment, talent, resources, and a large- 
volume practice. It has surgeon-, team-, and institutionspecific learning curves that allow best results only in the hands of "skilled enthusiasts."-11 While there are signs that the uptake of TECAB may have increased both in North America and in European countries, ${ }^{12}$ much of its use is currently restricted to harvesting the left internal thoracic artery, whereas conventional MICS CABG appears to be a much more rapidly developing multivessel platform. Nonetheless, Dr Balkhy demonstrates to us what is possible with robotic technology in the hands of a dedicated robotic surgeon and as a culmination of skilled teamwork, dedication, and leadership. It remains imperative, however, that we carefully anticipate, measure, and prepare for each step when such a demanding endeavor as developing a TE$\mathrm{CAB}$ program is undertaken.

\section{References}

1. Toeg H, Al-Atassi T, Labinaz M, Le May M, Ruel M. Hybrid approach for coronary artery revascularization: where do we stand? Curr Opin Cardiol. 2014;29: $534-41$.

2. Balkhy HH. Robotic totally endoscopic coronary artery grafting bypass grafting: it's now or never! J Thorac Cardiovasc Surg Tech. 2021;10:153-7.
3. Gobolos L, Ramahi J, Obeso A, Bartel T, Hogan M, Traina M, et al. Robotic totally endoscopic coronary artery bypass grafting: systematic review of clinical outcomes from the past two decades. Innovations (Phila). 2019;14:5-16.

4. Guo MH, Wells GA, Glineur D, Fortier J, Davierwala PM, Kikuchi K, et al. Minimally Invasive coronary surgery compared to STernotomy coronary artery bypass grafting: the MIST trial. Contemp Clin Trials. 2019;78:140-5.

5. Manuel L, Fong LS, Wolfenden H, Bassin L. Is totally endoscopic coronary artery bypass grafting compared with minimally invasive direct coronary artery bypass grafting associated with superior outcomes in patients with isolated left anterior descending disease? Ann Med Surg (Lond). 2020;57:264-7.

6. Kofler M, Schachner T, Reinstadler SJ, Stastny L, Dumfarth J, Wiedemann D, et al. Comparative analysis of perioperative and mid-term results of TECAB and MIDCAB for revascularization of anterior wall. Innovations (Phila). 2017; 12:207-13.

7. Lapierre H, Chan V, Sohmer B, Mesana TG, Ruel M. Minimally invasive coronary artery bypass grafting via a small thoracotomy versus off-pump: a casematched study. Eur J Cardiothorac Surg. 2011;40:804-10.

8. McGinn JT Jr, Usman S, Lapierre H, Pothula VR, Mesana TG, Ruel M. Minimally invasive coronary artery bypass grafting: dual-center experience in 450 consecutive patients. Circulation. 2009;120:S78-84.

9. Lee JD, Srivastava M, Bonatti J. History and current status of robotic totally endoscopic coronary artery bypass. Circ J. 2012;76:2058-65.

10. Robicsek F. Robotic cardiac surgery: time told! J Thorac Cardiovasc Surg. 2008; 135:243-6.

11. Une D, Lapierre H, Sohmer B, Rai V, Ruel M. Can minimally invasive coronary artery bypass grafting be initiated and practiced safely? A learning curve analysis. Innovations (Phila). 2013;8:403-9.

12. Pettinari M, Navarra E, Noirhomme P, Gutermann H. The state of robotic cardiac surgery in Europe. Ann Cardiothorac Surg. 2017;6:1-8. 